\title{
Zr doped $\beta$-rhombohedral boron: widely variable Seebeck coefficient and structural properties
}

\author{
Oksana Sologub $^{1,2, a}$, Leonid Salamakha ${ }^{2}$, Berthold Stöger $^{3}$, Yuichi Michiue $^{1}$, Takao Mori ${ }^{1, a}$ \\ ${ }^{1}$ National Institute for Materials Science, MANA, Namiki 1-1, Tsukuba, 305-0044, Japan \\ ${ }^{2}$ Institute of Solid State Physics, TU Wien, A-1040 Vienna, Austria \\ ${ }^{3}$ Institute for Chemical Technologies and Analytics, Vienna University of Technology, A- \\ 1040 Vienna, Austria
}

\begin{abstract}
The doping effect of zirconium on the structure, Seebeck coefficient and electrical resistivity of $\beta$-rhombohedral $\mathrm{B}$ was studied for the metal rich concentration range $Z_{\mathrm{x}} \mathrm{B}_{100-\mathrm{x}}$, $1.88 \leq \mathrm{x} \leq 2.75$. Structural studies proved the $\mathrm{Zr}$ atoms mainly in $E$ and $D$ voids for the metal rich compositions, and also elucidated the minor $\mathrm{Zr}$ occupancies of the $N, F$ and $A_{1}$ holes. Seebeck coefficients were effectively shifted within a wide range of positive and negative values by varying the $\mathrm{Zr}$ content ( $p$-type: $S_{\max } \sim+420 \mu \mathrm{VK}^{-1}$ at $673 \mathrm{~K}$ for x=1.88; $n$-type: $S_{\max }$ $\sim-670 \mu \mathrm{VK}^{-1}$ at $473 \mathrm{~K}$ for $\mathrm{x}=2.74$ ). Electrical resistivities generally followed the Mott's relation for the variable-range hopping. Excellent compositional agreement has been observed between structural and thermoelectric properties discontinuities.
\end{abstract}

Keywords: $\beta$-rhombohedral boron; Zr-doping; $p / n$ transition

${ }^{a}$ Corresponding authors: oksana.sologub@univie.ac.at; Mori.Takao@nims.go.jp 


\section{Introduction}

Boron and borides are considered to be promising thermoelectric (TE) materials for use at high temperatures of more than $1300 \mathrm{~K}$ [1-6], however, their properties still need to be developed further to enable practical use. Regarding elemental boron, the structure of $\beta$ rhombohedral $(\beta-r h)$ B (space group $R \overline{3} m)$ [7-11] has been extensively studied with respect to its ability to accommodate interstitially different kinds of foreign atoms [12-14]. It has been shown that metal doping into $\beta$-rh $\mathrm{B}$ can control the bonding nature in and between the clusters, delivering variation of physical properties such as electrical and thermal conductivities and Seebeck coefficient $[13,15-20]$. The interstitial doping of $\beta$-rh B by certain $3 d$-metals (e.g. V, $\mathrm{Cr}, \mathrm{Fe}, \mathrm{Ni}, \mathrm{Cu}$ ) led to negative values of TE power in the originally $p$-type semiconducting material in certain temperature ranges $[13,21]$; the structural and electronic properties of some solid solutions (i.e. $\mathrm{V}: \mathrm{B}, \mathrm{Fe}: \mathrm{B}, \mathrm{Cu}: \mathrm{B}$ ) have been consistently studied by different research groups $[13,15,22,23]$.

Information on physical properties of larger $d$-metals $\beta$-rh B solid solutions is scarce. A partial crystal structure of $\mathrm{Zr}$-doped $\beta$-rh $\mathrm{B}$ exhibiting the formula $\mathrm{ZrB}_{\sim 51}$ has been reported in the late seventies from powder X-ray diffraction data within a series of works mainly focused on elucidation of details on positional and occupancy parameters of transition metal atoms in the cavities of the boron lattice [24]. Later on [12] detailed structure analysis has been made for $\mathrm{Zr}$ sites distribution in the $\beta$-rh $\mathrm{B}$ crystal with $\mathrm{Zr}$ : $\mathrm{B}$ ratio $1: 143$, exhibiting as low dopant content as $\sim 0.69$ at.\%. Both studies showed different results regarding dopant atom site preferences, however they are evidence of rather high solid solubility of such a large transition element in $\beta$-rh $\mathrm{B}$. Contrasting data are available for the TE properties of $\mathrm{Zr}$ doped $\beta$-rh $\mathrm{B}$ showing highly positive (for $\mathrm{Zr}_{1.0} \mathrm{~B}_{105}$ and $\mathrm{Zr}_{0.8} \mathrm{~B}_{105}[18,25]$ ), and slightly negative (for $\mathrm{Zr}_{1.0} \mathrm{~B}_{105}$ [26]) values of Seebeck coefficient in the temperature ranges $200 \mathrm{~K}$ $300 \mathrm{~K}$ and $300 \mathrm{~K}-500 \mathrm{~K}$ respectively. In view of these inconsistencies and since the 
structure determination from powder diffraction data of $\mathrm{ZrB}_{\sim 51}$ was only of a rather preliminary nature, in the current study we i) aimed to clarify the structure of metal rich $\mathrm{Zr}$ doped $\beta$-rh $\mathrm{B}$ including the details of boron atom framework and dopant sites preferences as well as we ii) undertook the task to shed a light on the TE properties and their compositional dependence within the studied solubility range.

\section{Experimental procedure}

2.1. High temperature synthesis (HTS)

The proper weight ratios of amorphous boron (3N, SB-Boron Inc., USA) and zirconium oxide (3N, Koujundo Kagaku Co., Japan) were well mixed in mortars and compacted by cold iso-static pressing into cylindrical bars applying pressure of $300 \mathrm{MPa}$. The compacted rod was placed in a crucible made from sintered $\mathrm{BN}$ which was inserted into a graphite susceptor. The reaction process was performed under dynamic vacuum at a predetermined temperature of about $2073 \mathrm{~K}-2173 \mathrm{~K}$ for $4 \mathrm{~h}-8 \mathrm{~h}$ using a radio frequency (RF) induction furnace; afterwards the setup was cooled down in $1 \mathrm{~h}$ to room temperature. After synthesis, the samples were substantially surface cleaned, powderized, compacted and annealed for $4 \mathrm{~h}$ at $1973 \mathrm{~K}$.

\subsection{Spark plasma sintering (SPS)}

For SPS, each sample was pulverized in a mortar to $\mu \mathrm{m}$-size of particles, inserted in a $10 \mathrm{~mm}$ graphite die and set in the middle of the spark-plasma chamber of a Dr. Sinter 1080 apparatus (Fuji Denpa Kogyo Inc.). The sintering was performed after evacuating the chamber and afterwards filling with Ar to $1 \mathrm{~atm}$. The maximum applied pressure, temperature and holding time were $60 \mathrm{MPa}, 1923 \mathrm{~K}$ and 5 min respectively. 


\subsection{Single crystal X-ray diffraction (XRD)}

Single crystals were isolated from the fragmented melted portions of $\mathrm{ZrB}_{\sim 45}$ samples. Single crystal XRD data were collected on a Bruker APEX II diffractometer (CCD detector, $\kappa$-geometry, Mo K $\alpha$ radiation) (single crystal I). Orientation matrix and unit cell parameters were derived with the help of the program DENZO; multi-scan absorption correction was applied using the program SADABS; frame data were reduced to intensity values applying the SAINT-Plus package [27,28]. Alternatively, a different crystal (single crystal II) was measured with a four-circle diffractometer Rigaku AFC 7R. The Laue symmetry and unit cell dimensions were determined from the measurements and least square refinement of 25 reflections centered in the range $8 \leq 2 \theta \leq 50$; the absorption correction was performed applying azimuthal scan ( $\psi$-scan) method [29]. Possible space groups were found out from the analysis of systematic absences performed with the help of program ABSEN [30,31]. The structures were solved by direct methods and refined with the SHELXS-97 [32] and SHELXL-97 [33] programs, respectively. The atom coordinates were standardized with the program STRUCTURE TIDY [34]. Further details concerning the single crystal XRD experiments and data refinement are summarized in Tables 1-2.

\subsection{Powder XRD}

The phase compositions of the reacted products were verified from powder XRD data using a standard high-resolution powder X-ray diffractometer (R-2000, Rigaku Co.) with $\mathrm{CuK \alpha}$ radiation. The structural details have been studied from the samples obtained after TE properties measurements. Structure refinements were performed from powder X-ray intensity data collected in the range $3^{\circ} \leq 2 \theta \leq 110^{\circ}\left(120^{\circ}\right)$ with the scanning step width $0.02^{\circ}$ and 
sampling time $15 \mathrm{sec} / \mathrm{step}$ with full-profile Rietveld method using the program FULLPROF [35] applying the initial atomic positions obtained from the single crystal XRD data.

\subsection{TE properties measurements}

For thermoelectric properties measurements, the samples were additionally heat treated for about 2 hours at $873 \mathrm{~K}$ in He atmosphere in the ULVAC ZEM-2 equipment. Resistivity and TE power were measured from cut bar-shaped (in general about $5 \mathrm{~mm} \times 5 \mathrm{~mm}$ $\times 8 \mathrm{~mm}$ ) HTS and SPS samples by using the four probe method and differential method respectively.

\section{Results and discussion}

\subsection{Structure refinement from single crystal XRD data}

The space group $R \overline{3} m$ classically used for the refinement of $\beta-r h \mathrm{~B}$ structure was found to be compatible with the observed extinction rules for both sets of single crystal intensities data. Two Zr and several B atom sites were determined with direct methods; the remaining atom sites were localized from analysis of the difference-Fourier maps revealing the structure model exhibiting in total 15 atom positions of $\mathrm{B}$ and 2 atom sites of $\mathrm{Zr}$ (recognized as commonly denoted D and E voids). In further description the boron sites have the same notation as that used in Refs. $[7,12]$. No additional B atoms (B16-B20) between the $\mathrm{B}_{12}$ icosahedra such as were observed in the 20 -atom position's $\beta$-rh $\mathrm{B}$ structure [7] and in the structures of $\mathrm{ZrB}_{\sim 51}$ [24] and $\mathrm{Zr}_{0.72} \mathrm{~B}_{105}$ [12], were found in the current crystals. In agreement with the results of previous studies on the crystal structures of $\mathrm{Zr}-, \mathrm{Mg}$ - and $\mathrm{Sc}$-doped $\beta$-rh $\mathrm{B}$, the peaks of residual electron densities were observed in the sites $F\left(0.59 \mathrm{e}^{-} / \AA^{3}\right.$ in $18 g$, $x=0.38), \mathrm{N}\left(0.57 \mathrm{e}^{-} / \AA^{3}\right.$ in $\left.18 h(x, \bar{x}, z), x=0.787, z=0.090\right)\left(\right.$ crystal I) and $A_{l}\left(1.08 \mathrm{e}^{-} / \AA^{3}\right.$ in $6 c$, 
$z=0.36), F\left(0.96 \mathrm{e}^{-} / \AA^{3}\right.$ in $\left.18 g, x=0.38\right)$ (crystal II). Although the refinement of site occupancy parameters assuming the population of these voids by $\mathrm{Zr}$ rendered rather low values (Table 2), the accounting for atoms in $F, N$ and $A_{1}$ sites led, similarly to other metal-doped icosahedral borides [36-38], to a significant improvement of the reliability factors and to a substantive decrease of the remaining residual electron densities in the Fourier density maps. The refinements of occupancies of the atom sites rendered the range of metal:boron ratios close to $1: 40-1: 41$ which is significantly higher as compared to the $\mathrm{Zr} / \mathrm{B}$ ratios reported previously [12,24]. Refined positional and displacement parameters, and site occupation factors are given in Tables 1-2 and Table 1 in Supporting Information; selected interatomic distances are listed in Table 2 Supporting Information.

Table 1. Crystallographic data for $\mathrm{Zr}$ doped $\beta$-rh $\mathrm{B}(R \overline{3} m$; No.166; Z=3).

\begin{tabular}{|c|c|c|}
\hline Compound & $\mathrm{ZrB}_{41.101}$ (crystal I) & $\mathrm{ZrB}_{39.967}$ (crystal II) \\
\hline Formula from refinement & $\mathrm{Zr}_{2.5014} \mathrm{~B}_{102.809}\left(\mathrm{Zr}_{7.5042} \mathrm{~B}_{308.4264}\right)$ & $\mathrm{Zr}_{2.58} \mathrm{~B}_{103.116}\left(\mathrm{Zr}_{7.74} \mathrm{~B}_{309.348}\right)$ \\
\hline Nominal composition & $\mathrm{Zr}_{2.375} \mathrm{~B}_{97.625}$ & $\mathrm{Zr}_{2.441} \mathrm{~B}_{97.559}$ \\
\hline Lattice parameters $[\AA]$ & $\mathrm{a}=10.9363(5), \mathrm{c}=24.0253(10)$ & $\mathrm{a}=10.939(1), \mathrm{c}=24.029(6)$ \\
\hline Volume $\left[\AA^{3}\right]$ & $2488.5(1)$ & $2490.0(9)$ \\
\hline$\rho_{\text {calc }}\left[\mathrm{g} / \mathrm{cm}^{3}\right]$ & 2.681 & 2.703 \\
\hline Diffractometer & Bruker APEX II, MoK $\alpha$ & Rigaku AFC 7R, MoK $\alpha$ \\
\hline $2 \theta_{\max }\left[^{\circ}\right]$ & 59.98 & 63.98 \\
\hline $\mathrm{N}(\mathrm{hkl})$ measured & 11318 & 10704 \\
\hline $\mathrm{N}(\mathrm{hkl})$ unique & 890 & 1099 \\
\hline $\mathrm{N}(\mathrm{hkl})$ observed $\left(\mathrm{F}_{\mathrm{hkl}}>4 \sigma(\mathrm{F})\right)$ & 669 & 449 \\
\hline Refined parameters & 115 & 108 \\
\hline \multirow[t]{2}{*}{ Reliability factors } & $\mathrm{R}_{\mathrm{F}}^{2}=\Sigma\left|\mathrm{F}_{\mathrm{o}}^{2}-\mathrm{F}_{\mathrm{c}}^{2}\right| / \Sigma \mathrm{F}_{\mathrm{o}}^{2}=0.036$ & $\mathrm{R}_{\mathrm{F}}^{2}=\Sigma\left|\mathrm{F}_{\mathrm{o}}^{2}-\mathrm{F}_{\mathrm{c}}^{2}\right| / \Sigma \mathrm{F}_{\mathrm{o}}^{2}=0.054$ \\
\hline & $\mathrm{GooF}=0.990$ & $\mathrm{GooF}=0.796$ \\
\hline Extinction coefficient & $0.000(1)$ & $0.000(6)$ \\
\hline Residual electron density $\left[\mathrm{e}^{-} / \AA^{3}\right]$ (max; min) & $+0.46 ;-0.37$ & $+0.70 ;-1.40$ \\
\hline
\end{tabular}




\subsection{Structure description}

The structure of $\beta$-rh $\mathrm{B}$ exhibits two kinds of icosahedral boron atom networks alternating along the $c$ direction [39] (Fig. 1). The networks of type II icosahedra which are composed of B1, B2, B7 and B9 and located at $z=0,1 / 3$ and $2 / 3$ can be seen as Kagomé 6363nets. The nets appearing at $z=1 / 6,3 / 6$ and $5 / 6$ are formed by the groups of three face-fused icosahedra (type III; built by B3, B4, B8, B10, B11, B12, B13 and B14) with a general formula $\mathrm{B}_{28}$ and type $\mathrm{I}$ icosahedra (constructed of $\mathrm{B} 5$ and $\left.\mathrm{B} 6\right)$. The $\left[\mathrm{B}_{28}\right]$ clusters from different layers inter-link via boron atoms $(\mathrm{B} 15$ in $3 a, 0,0,0)$ in such a way that the $\left[\mathrm{B}_{28}\right]$ and $\left[\mathrm{B}_{12}\right]$ units are located below and above hexagons and triangles of the Kagomé 6363-nets. The tri-icosahedra are generally found with atomic defects on particular sites $[9,40]$; in case of $\beta-r h \mathrm{~B}$ structure, the partial occupancy is well established leading, instead of $\left[\mathrm{B}_{28}\right]$, to the boron deficient actual formula. The structure exhibits several interstitial atomic positions which can accommodate boron or other atoms if partially occupied $[7,12]$.

The refinement of occupancy parameters of partially occupied sites in Zr-doped $\beta$-rh B from powder XRD data [24] using the atom coordinates of $\mathrm{Sc}$ doped $\beta$-rh $\mathrm{B}$ structure [41] as the start values revealed the $\mathrm{Zr}: \mathrm{B}$ ratio of $\sim 1: 51(1.93 \mathrm{at} \% \mathrm{Zr})$ exhibiting $52.8 \%, 14.5 \%$, $27.9 \%, 18.1 \%$ and $0.7 \%$ occupancy for B13 (18h), B16 (18h), Zr2 (18h, D void), Zr3 (6c, E void) and $\operatorname{Zr} 4(18 g, 0.37,0,1 / 2, F$ void) respectively (a=10.9564 $\AA, c=24.0201 \AA)$. Subsequent work [12] on the B-rich crystal reported three atom sites of $\mathrm{Zr}$ (in $A_{1}, D$, and $E$ voids) displaying rather distinct from previous study, occupation percentages on both $\mathrm{Zr}$ $(1.7 \%, 8.1 \%$ and $10.7 \%$ respectively) and $\mathrm{B}(62.5 \%$ for $\mathrm{B} 13$ and $35.8 \%$ for $\mathrm{B} 16)$ atom sites which leads to as low dopant/boron ratio as 1:143 (0.69 at\% Zr). Our single crystal XRD study results show that at $\sim 2.4$ at.\% $\mathrm{Zr}$ doping level, the $D$ and $E$ voids are the main ones that are occupied by metal atom whereas the occupancies of other interstitial metal sites $(F, N$ and $A_{1}$ ) are very small, ranging within $0.33 \%-0.7 \%$. 
Table 2. Atomic coordinates and equivalent isotropic displacement parameters ${ }^{a, b}$ (in $\left[\AA^{2}\right]$ ) for $\mathrm{Zr}$ doped $\beta-r h \mathrm{~B}$ as obtained from single crystal XRD.

\begin{tabular}{|c|c|c|}
\hline Atom & $\mathrm{ZrB}_{41.101}$ & $\mathrm{ZrB}_{39.967}$ \\
\hline $\mathrm{B} 1$ in $36 i(x, y, z)$ & $\mathrm{x}=0.0008(2), \mathrm{y}=0.1725(2), \mathrm{z}=0.3249(1)$ & $\mathrm{x}=0.0012(4), \mathrm{y}=0.1728(4), \mathrm{z}=0.3247(2)$ \\
\hline occ.; $\mathrm{U}_{\mathrm{eq}}$ & $1.0 ; 0.0071(4)$ & $1.0 ; 0.0076(7)$ \\
\hline $\mathrm{B} 2$ in $36 i(x, y, z)$ & $\mathrm{x}=0.0144(2), \mathrm{y}=0.3732(2), \mathrm{z}=0.0378(1)$ & $\mathrm{x}=0.0140(4), \mathrm{y}=0.3728(4), \mathrm{z}=0.0379(1)$ \\
\hline occ.; $\mathrm{U}_{\mathrm{eq}}$ & $1.0 ; 0.0064(4)$ & $1.0 ; 0.0052(7)$ \\
\hline $\mathrm{B} 3$ in $36 i(x, y, z)$ & $\mathrm{x}=0.0445(2), \mathrm{y}=0.2626(2), \mathrm{z}=0.0821(1)$ & $\mathrm{x}=0.0450(4), \mathrm{y}=0.2630(4), \mathrm{z}=0.0823(2)$ \\
\hline occ.; $\mathrm{U}_{\mathrm{eq}}$ & $1.0 ; 0.0066(4)$ & $1.0 ; 0.0053(7)$ \\
\hline B4 in $36 i(x, y, z)$ & $\mathrm{x}=0.2520(2), \mathrm{y}=0.0149(2), \mathrm{z}=0.1534(1)$ & $\mathrm{x}=0.2517(4), \mathrm{y}=0.0154(4), \mathrm{z}=0.1535(2)$ \\
\hline occ.; $\mathrm{U}_{\mathrm{eq}}$ & $0.9964(7)^{c} ; 0.0065(4)^{d}$ & $0.993(1)^{c} ; 0.0067(7)^{d}$ \\
\hline $\mathrm{B} 5$ in $18 h(x, \bar{x}, z)$ & $\mathrm{x}=0.3873(2), \mathrm{z}=0.1100(1)$ & $\mathrm{x}=0.3876(3), \mathrm{z}=0.1099(2)$ \\
\hline occ.; $\mathrm{U}_{\mathrm{eq}}$ & $1.0 ; 0.0053(5)$ & $1.0 ; 0.0058(7)^{d}$ \\
\hline B6 in $18 h(x, \bar{x}, z)$ & $\mathrm{x}=0.4173(1), \mathrm{z}=0.1797(1)$ & $\mathrm{x}=0.4172(3), \mathrm{z}=0.1796(2)$ \\
\hline occ.; $\mathrm{U}_{\mathrm{eq}}$ & $1.0 ; 0.0039(5)$ & $1.0 ; 0.0046(9)$ \\
\hline B7 in $18 h(x, \bar{x}, z)$ & $\mathrm{x}=0.4417(2), \mathrm{z}=0.0548(1)$ & $\mathrm{x}=0.4410(3), \mathrm{z}=0.0550(2)$ \\
\hline occ.; $\mathrm{U}_{\mathrm{eq}}$ & $1.0 ; 0.0065(6)$ & $1.0 ; 0.0058(7)^{d}$ \\
\hline $\begin{array}{l}\text { B8 in } 18 h(x, \bar{x}, z) \\
\text { occ.; } \mathrm{U}_{\mathrm{eq}}\end{array}$ & $\begin{array}{l}x=0.5014(2), \mathrm{z}=0.1937(1) \\
1.0 ; 0.0060(5)\end{array}$ & $\begin{array}{l}x=0.5017(3), \mathrm{z}=0.1940(2) \\
1.0 ; 0.0066(9)\end{array}$ \\
\hline B9 in $18 h(x, \bar{x}, z)$ & $\begin{array}{l}\mathrm{x}=0.5373(2), \mathrm{z}=0.0659(1) \\
1.0 ; 0.0059(5)\end{array}$ & $\begin{array}{l}\mathrm{x}=0.5374(3), \mathrm{z}=0.0656(2) \\
1.0 ; 0.0061(9)\end{array}$ \\
\hline $\begin{array}{l}\text { occ.; } \mathrm{U}_{\text {eq }} \\
\mathrm{B} 10 \text { in } 18 h(x, \bar{x}, z)\end{array}$ & $\mathrm{x}=0.5642(1), \mathrm{z}=0.1347(1)$ & $\mathrm{x}=0.5642(3), \mathrm{z}=0.1350(2)$ \\
\hline occ.; $\mathrm{U}_{\mathrm{eq}}$ & $1.0 ; 0.0059(6)$ & $1.0 ; 0.0066(9)$ \\
\hline $\begin{array}{l}\text { B13 in } 18 h(x, \bar{x}, z) \\
\text { occ.; } \mathrm{U}_{\mathrm{eq}}\end{array}$ & $\begin{array}{l}x=0.6110(3), z=0.2766(2) \\
0.642(10) ; 0.013(1)\end{array}$ & $\begin{array}{l}x=0.6104(5), z=0.2769(4) \\
0.70(2) ; 0.014(2)\end{array}$ \\
\hline $\begin{array}{l}\text { B11 in } 18 h(x, \bar{x}, z) \\
\text { occ.; } \mathrm{U}_{\mathrm{eq}}\end{array}$ & $\begin{array}{l}\mathrm{x}=0.7239(2), \mathrm{z}=0.1604(1) \\
1.0 ; 0.0083(6)^{d}\end{array}$ & $\begin{array}{l}\mathrm{x}=0.7238(3), \mathrm{z}=0.1599(2) \\
1.0 ; 0.0084(10)\end{array}$ \\
\hline $\mathrm{B} 12$ in $18 h(x, \bar{x}, z)$ & $\mathrm{x}=0.7570(2), \mathrm{z}=0.2305(1)$ & $\mathrm{x}=0.7568(3), \mathrm{z}=0.2307(2)$ \\
\hline occ.; $\mathrm{U}_{\mathrm{eq}}$ & $1.0 ; 0.0058(6)$ & $1.0 ; 0.0061(10)$ \\
\hline B14 in $6 c(0,0, z)$ & $z=0.1$ & $z=0.1$ \\
\hline occ.; $\mathrm{U}_{\mathrm{eq}}$ & $1.0 ; 0$ & $1.0 ; 0$ \\
\hline B15 in $3 a(0,0,0)$ occ.; $\mathrm{U}_{\mathrm{eq}}$ & $1.0 ; 0.018(2)^{e}$ & $1.0 ; 0.014(3)$ \\
\hline $\mathrm{Zr} 2$ in $18 h(x, \bar{x}, z)(D)$ & $x=0.53595(4), z=0.34227(3)$ & $x=0.53605(10), z=0.34248(7)$ \\
\hline occ.; $\mathrm{U}_{\mathrm{eq}}$ & $0.299(2) ; 0.0072(3)$ & $0.306(2) ; 0.0088(5)$ \\
\hline $\mathrm{Zr} 3$ in $6 c(0,0, z)(E)$ & $\mathrm{z}=0.26437(5)$ & $\mathrm{z}=0.26426(10)$ \\
\hline occ.; $\mathrm{U}_{\mathrm{eq}}$ & $0.333(2) ; 0.0040(4)$ & $0.345(4) ; 0.0043(7)$ \\
\hline $\mathrm{Zr} 44$ in $18 g(x, 0,1 / 2)(F)$ & $x=0.376(5)$ & $x=0.385(7)$ \\
\hline occ.; $\mathrm{U}_{\mathrm{eq}}$ & $0.0036(7)^{c} ; 0.0065(4)^{d}$ & $0.007(1)^{c} ; 0.0067(7)^{d}$ \\
\hline $\operatorname{Zr} 11$ in $18 h(x, \bar{x}, z)(N)$ & $x=0.785(3), z=0.092(3)$ & - \\
\hline occ.; $\mathrm{U}_{\mathrm{eq}}$ & $0.0033(7) ; 0.0083(6)^{d}$ & \\
\hline $\mathrm{Zr77}$ in $6 c(0,0, z)\left(A_{1}\right)$ & - & $z=0.360(6)$ \\
\hline occ.; $\mathrm{U}_{\mathrm{eq}}$ & - & $0.006(2) ; 0.0058(7)^{d}$ \\
\hline \multicolumn{3}{|c|}{$\begin{array}{l}{ }^{a} \mathrm{U}_{\mathrm{eq}} \text { is defined as one-third of the trace of the orthogonalized } \mathrm{U}_{\mathrm{ij}} \text { tensor; }^{b} \text { anisotropic } \\
\text { displacement parameters are listed in Table } 1 \text { Supporting Information; }{ }^{c} \text { site occupancy } \\
\text { factors have been constrained; }{ }^{d} \text { displacement parameters have been constrained to be } \\
\text { equivalent for following groups of atoms: i) } \mathrm{B} 4, \mathrm{Zr} 44 \text {; ii) } \mathrm{B} 11, \mathrm{Zr} 11 \text {; iii) } \mathrm{Zr} 77, \mathrm{~B} 5, \mathrm{~B} 7 \text {; }{ }^{e}\end{array}$} \\
\hline
\end{tabular}


The $D$ void is large enough to accommodate the atoms of the first transition metal row, however it is rather small for $\mathrm{Zr}$, delivering too short $\mathrm{Zr2}$-B13 distances for full occupancy of both atom sites simultaneously (Table 2 Supporting Information). Similarly to the structure of Sc-doped $\beta$-rh B [41], the occupancy value of B13 site is close to $2 / 3(64.2 \%$ and $70.0 \%$ ) whereas the $D$ void is filled for about $30 \%$ with $\mathrm{Zr} 2$. The information on $E$ void occupancy is much less extensive than that for the $D$ hole. Because of the large distance between the center of the hole to the neighboring atoms (i.e. 2.408(2) $\AA$ in pure $\beta$-rh $\mathrm{B}$ ), the larger ions such as $\mathrm{Li}, \mathrm{Mg}, \mathrm{Sc}, \mathrm{Hf}$ and $\mathrm{Zr}$ fit well into the $E$ void and show high level of occupancy, e.g. full and almost full (91\%) occupancy for $\mathrm{Li}[42,43]$ and $\mathrm{Mg}$ [44-46] respectively and $72.7 \%$ for $\mathrm{Sc}$ [41]. In comparison with $\mathrm{Li}, \mathrm{Mg}$ and $\mathrm{Sc}$ dopants, the $\mathrm{Zr}$ exhibits rather medium degree of filling of the $E$ void, $33.3 \%-34.5 \%$. The adjacent $A_{1}$ void $\left(d_{\mathrm{Zr3}-\mathrm{Zr} 77}=2.3 \AA\right)$ remains almost unoccupied (Occ. Zr77 is $\left.0.7 \%\right)$ exhibiting short Zr-B distances ranging within 2.07-2.24 $\AA$; obviously $A_{l}$ hole is too small for Zr. Refinements of both single crystal data sets showed a very minor occupancy of the $F$ site as well. Insertion of $\mathrm{Zr}$ in $18 g\left(x, 0, \frac{1}{2}\right)$ position ( $F$ site) leads to the partial replacement of two boron atoms (namely $\mathrm{B} 4$ ) of two neighboring $\left[\mathrm{B}_{28}\right]$ units by one metal atom at an intermediate position. Mixed B/metal atom occupancy of split icosahedral site has already been observed for some metal doped $\beta$-rh $\mathrm{B}$ structures $[38,44-46]$ including $\mathrm{ZrB}_{\sim 51}[24]$ as well as more recently for other higher borides [36, 37]. Additionally, a new $N$ void $(18 h)$ reported for the first time for Mg-doped $\beta$-rh B [44-46] was found to be populated for only $0.3 \%$ by $\mathrm{Zr} 11$ in one of the studied single crystals. Both $D$ and $E$ sites have 15 close boron neighbours (Fig. 1d,e); the $\operatorname{Zr44}\left(F\right.$ void), $\operatorname{Zr11}\left(N\right.$ void) and $\operatorname{Zr77}\left(A_{1}\right.$ void) are surrounded by 10,16 and 12 boron atoms respectively (Fig. 1f-h). The Zr-B distances range within 2.07 (Zr77-B1) and 2.62 (Zr11-B13) except the short distances for the B4/Zr44 atoms located in split atom position. 
The boron networks of $\mathrm{Zr}$ doped $\beta$-rh $\mathrm{B}$ (Fig. 1b,c) agree closely with that of $\beta$-rh $\mathrm{B}$ [7], however the interstitial atoms B16-B20 situated in a partially occupied positions in undoped $\beta$-rh $\mathrm{B}$ have not been detected in current single crystal study thus revealing the structure with only $15 \mathrm{~B}$ atom positions. Further, alike in $\mathrm{ScB}_{28}$ [41], $\mathrm{ZrB}_{\sim 51}$ [24] as well as more recently in Mg-doped $\beta$-rh B structures [44-46], the B4 site shows slight underoccupation in both crystals.

The B-B distances within the icosahedra cover the range $1.710 \AA$ (1.706 $\AA$ ) (B6-B6, icosahedron type I) - $1.896 \AA$ (1.892 $\AA$ ) (B3-B3, icosahedron type III) in single crystals I and II respectively; the shortest contact distance decreases upon doping in comparison with corresponding $\mathrm{B}-\mathrm{B}$ distance in the structure of 20 -atom positions' $\beta$-rh $\mathrm{B}\left(d_{\mathrm{B} 6-\mathrm{B} 6}=1.75 \AA\right.$ [7]). Alike in other icosahedral borides, the B-B distance between icosahedra in $\mathrm{Zr}$-doped $\beta$-rh $\mathrm{B}$ structure are shorter than the B-B distances within icosahedra. The icosahedron I exhibits shorter B-B contact distances as compare to $\mathrm{B}_{28}$-unit and icosahedron II showing the values between $1.710 \AA-1.771 \AA / 1.706 \AA-1.782 \AA$ vs $1.736 \AA-1.896 \AA / 1.735 \AA-1.892 \AA$ and $1.803 \AA-1.880 \AA / 1.815 \AA-1.876 \AA$ (in single crystal I / single crystal II respectively). The distance between $\mathrm{B} 13$ atoms, at which the icosahedra condense into $\mathrm{B}_{28}$-unit $(1.828 \AA / 1.848$ $\AA$ ), is also significantly shorter if compared to the B13-B13 bond length in $\beta$-rh B (1.898 $\AA$ ).

\subsection{Dopant atom site preferences from powder XRD data}

Powder XRD patterns of $\mathrm{Zr}_{\mathrm{x}} \mathrm{B}_{100-\mathrm{x}}(1.88 \leq \mathrm{x} \leq 2.76)$ recorded after heat-treating procedure for all samples exhibited the spectrum of metal-doped $\beta$-rh B structure. Examination of intensity distribution within the series of diffractograms spotted out the liability of different site occupancies by $\mathrm{Zr}$ atoms depending on metal content of the sample; this supposition was further confirmed from Rietveld refinements (Table 3, Fig. 2). The structure models obtained from single crystal X-ray diffraction studies presented above were 
used for Rietveld refinements of powder data; the $D, E, F, N$ and $A_{l}$ doping sites were selected for the refinements of Zr occupancy. The B16 atom site appeared to be populated only in the sample with higher B content, while the occupancies of $N, F$ and $A_{l}$ void were found to be very small within the entire investigated concentration range in good agreement with the results of single crystal structural studies (Tables 2-3). With respect to refinement procedure, we should note that introduction of $\mathrm{Zr}$ into the $F, N$, and $A_{1}$ voids in the starting atom model followed by further refinement of positional and occupancy parameters improves significantly the final reliability factors despite small filling percentage of corresponding atom sites. In good correspondence with single crystal results, the occupancy of D site does not exceed $30 \%$; starting from about $17 \%$ at 1.88 at. $\% \mathrm{Zr}$, the occupancy of $D$ site rapidly increases and saturates above 2.4 at\% $\mathrm{Zr}$ (Fig. 3). In contrast, the occupancy of $E$ site increases rather moderately towards higher $\mathrm{Zr}$ content. Both $D$ - and $E$-site occupancy vs. $\mathrm{Zr}$ content dependencies show noticeable anomalies upon reaching ca 2.58 at.\% $\mathrm{Zr}$; the increase of $\mathrm{Zr}$ content within $\mathrm{Zr}_{2.58} \mathrm{~B}_{97.42-} \mathrm{Zr}_{2.75} \mathrm{~B}_{97.25}$ interval is mainly realized via increased population of $F$-, $N$ - and $A_{l^{-}}$sites (Table 3 ). In compliance with the features of atom sites occupancies, the lattice parameters $v s$. $\mathrm{Zr}$ content dependencies show anomalies above 2.58 at.\% (Fig. 4). Further doping (above 2.75 at.\% Zr) was not effective at our synthesis conditions due to considerable precipitation of secondary $\mathrm{ZrB}_{12}$ phase, particularly in the SPS sintered samples. 
Table 3.

Compositions, lattice constants and occupancies of partially occupied atom sites in the Zrdoped $\beta$-rh B (space group $R \overline{3} m$ ) as obtained from Rietveld refinements of powder XRD data $^{a, b}$ in comparison with the results obtained from single crystal XRD data refinements and literature data.

\begin{tabular}{ccccccclll}
\hline $\begin{array}{c}\text { Composition } \\
\text { (at. \%) }\end{array}$ & \multicolumn{1}{c}{ Lattice parameters $(\AA)$} & \multicolumn{9}{c}{ Atom site occupancy (\%) } \\
& $\mathrm{a}$ & $\mathrm{c}$ & $18 h$ & $6 c$ & $18 g$ & $18 h$ & $6 c$ & $18 h$ & \\
& & & $(\mathrm{Zr}, D)$ & $(\mathrm{Zr}, E)$ & $(\mathrm{Zr}, F)$ & $(\mathrm{Zr}, N)$ & $\left(\mathrm{Zr}, A_{1}\right)$ & $(\mathrm{B} 16)$ & \\
\hline $\mathrm{Zr}_{0.69} \mathrm{~B}_{99.31}$ & 10.932 & 23.849 & 8.1 & 10.7 & & & 0.17 & 35.8 & {$[12]$} \\
$\mathrm{Zr}_{1.96} \mathrm{~B}_{98.04}$ & 10.9564 & 24.0201 & 27.9 & 18.1 & 0.7 & & - & 14.5 & {$[24]$} \\
$\mathrm{Zr}_{1.88} \mathrm{~B}_{98.12}$ & $10.9492(9)$ & $23.939(2)$ & 16.8 & 32.8 & 3.4 & 1.6 & - & 14.1 & HTS, powder \\
$\mathrm{Zr}_{2.37} \mathrm{~B}_{97.63}$ & $10.9363(5)$ & $24.025(1)$ & 29.9 & 33.3 & 0.4 & 0.4 & - & - & HTS, SC \\
$\mathrm{Zr}_{2.44} \mathrm{~B}_{97.56}$ & $10.938(1)$ & $24.029(6)$ & 30.6 & 34.5 & 0.7 & - & 0.6 & - & HTS, SC \\
$\mathrm{Zr}_{2.38} \mathrm{~B}_{97.62}$ & $10.9395(7)$ & $24.007(2)$ & 25.7 & 38.2 & 1.9 & 1.3 & 0.2 & & SPS, powder \\
$\mathrm{Zr}_{2.58} \mathrm{~B}_{97.42}$ & $10.9382(6)$ & $24.002(2)$ & 26.9 & 40.8 & 2.7 & 1.9 & - & - & SPS, powder \\
$\mathrm{Zr}_{2.60} \mathrm{~B}_{97.40}$ & $10.9449(6)$ & $24.027(2)$ & 27.6 & 36.8 & 3.1 & 2.3 & 0.8 & - & SPS, powder \\
$\mathrm{Zr}_{2.74} \mathrm{~B}_{97.26}$ & $10.9425(7)$ & $24.028(2)$ & 27.0 & 40.7 & 3.9 & 3.5 & - & - & HTS, powder \\
$\mathrm{Zr}_{2.75} \mathrm{~B}_{97.25}$ & $10.9404(6)$ & $24.032(2)$ & 27.9 & 42.2 & 3.6 & 2.4 & - & - & HTS, powder \\
\hline$a$
\end{tabular}
$x, y, z)$ was fixed to determined value upon the refinement of occupancy of $\mathrm{Zr}$ in $18 \mathrm{~g}(F$ site $)$

\subsection{Electrical resistivity}

In general two mechanisms exist to describe the transport properties of lightly doped semiconductors, Mott's model for the variable-range hopping-type (VRH) resistivity [47] and phonon-assisted hopping conduction model of Emin and Holstein [48]. Both models have been found appropriate for a large number of materials, from piezoelectric semiconductors to graphene nanotubes. The dependence of resistivity for $\mathrm{Zr}$-doped $\beta$-rh $\mathrm{B}$ in the temperature region from $323 \mathrm{~K}$ to $873 \mathrm{~K}$ is shown in Fig. 5 on a logarithmic scale against $\mathrm{T}^{-1 / 4}$ in concord with the literature data on conductivity of $\beta$-rh $\mathrm{B}$ doped with other transition metals. Regardless of the $\mathrm{Zr}$ content, the resistivity plots in the chosen representation are following 
linear dependencies in agreement with the Mott's model for the variable-range hopping-type resistivity,

$$
\rho=\rho_{0} \exp \left\{\left(\frac{T_{0}}{T}\right)^{1 / 4}\right\}, T_{0}=\frac{60 \alpha^{3}}{\pi N\left(E_{f}\right) k_{B}}
$$

where $\rho_{0}$ is a constant, $T_{0}$ is Mott's characteristic temperature, $\alpha^{-1}$ is the localization length of the wave function of the carriers, $N\left(E_{f}\right)$ is the density of states on the Fermi level and $k_{B}$ is the Boltzmann constant. The value of electrical resistivity increases following the increase of $\mathrm{Zr}$ content until it saturates at 2.60 at. $\% \mathrm{Zr}$, notwithstanding differences in density of materials (relative densities in general varied as $\sim 50 \%$ and $\sim 80 \%$ for HTS and SPS samples respectively). The resistivity of the samples at low temperatures varies greatly (up to 3 orders) depending on $\mathrm{Zr}$ concentration; for Zr-rich samples, large decreases of the resistivity were observed with increase of the temperature.

The analysis with a phonon-assisted hopping conduction model,

$$
\rho=\frac{T}{C} \exp \left\{\frac{k_{B} T}{E}\right\}
$$

( $C$ is a constant and $E$ is the activation energy of mobility) was found to be inappropriate for the samples studied in current work.

\subsection{Thermopower}

Fig. 6 shows the variation of the Seebeck coefficient with temperature for various samples. Considering the analysis of resistivity one should expect the Seebeck coefficient to behave in agreement with VRH model, and thus follow the equation proposed by Brenig et al. (1973) [49]

$$
S \approx \frac{k_{B}^{2}}{64 q} T_{0}^{1 / 2} T^{1 / 2}\left\{N^{\prime}(E) / N(E)\right\}_{E_{f}}\left\{1+\left(T_{0} / T\right)^{1 / 4}\right\}
$$


where $q$ is a charge of carriers and $T_{0}$ is a constant inverse proportional to $N\left(E_{F}\right)$ and $E$ is the thermal activation energy of the mobility of carriers. More simple relations of $\mathrm{S} \propto\left(\mathrm{T}_{0} \mathrm{~T}\right)^{1 / 2} d(\ln \mathrm{N}(\mathrm{E})) /\left.d \mathrm{E}\right|_{\mathrm{E}_{\mathrm{F}}}$ was proposed by Zvyagin [50], while $S \sim T^{1 / 2}$ was proposed by Overhof [51]. In case if the phonon-assisted hopping-type conduction is dominant, the Seebeck coefficient tends to be proportional to the temperature

$$
S=\frac{\left(T \Delta S^{\prime}+E_{T}\right)}{q T}=A+B T,
$$

where $A$ and $B$ are constants, $\Delta S^{\prime}$ is the change in entropy due to the insertion of a carrier, $E_{T}$ is the average vibrational energy, and $q$ is the charge of carriers. However, the experimental results obtained for the $\mathrm{Zr}$ doped $\beta$-rh $\mathrm{B}$ do not completely follow any of the described models. While the $p$-type samples demonstrate a maximum of Seebeck coefficient in the range around $700 \mathrm{~K}$, the $n$-type samples clearly demonstrate a minimum in the medium temperature range. Similar behavior is explained for a V-doped $\beta$-rh $\mathrm{B}$ as a result of the combined influence of VRH conduction and band conduction [52]. In case of Zr-doped $\beta$-rh B we can state that the behavior of different carrier types should be considered from the point of view of different models.

Thus far, the TE properties have been studied for the boron rich $\mathrm{Zr}_{\mathrm{x}} \mathrm{B}_{100-\mathrm{x}}$ samples $(\mathrm{x}<1)$ in the temperature range $200-300 \mathrm{~K}$ [18]. In agreement with previous studies, our boron-rich $\mathrm{Zr}$-doped $\beta$-rh $\mathrm{B}$ samples up to $\mathrm{x} \leq 2.38\left(\mathrm{Zr}_{1.88} \mathrm{~B}_{98.12}-\mathrm{Zr}_{2.38} \mathrm{~B}_{97.62}\right)$ showed high positive values of thermoelectric power (Fig. 7). Towards higher $\mathrm{Zr}$ content, the sign of Seebeck coefficient shifts from positive to negative values reaching the extraordinary high negative values (almost $-670 \mu \mathrm{VK}^{-1}$ at $473 \mathrm{~K}$ ) for $2.74 \mathrm{at} \% \mathrm{Zr}$-doped $\beta$-rh $\mathrm{B}$. This is the first evidence of such high negative thermopower of transition metal solid solutions in $\beta$-rh $\mathrm{B}$. 


\section{Summary}

Up-to-now, very few transition metal dopants were reported to evoke negative Sebeck coefficients in $\beta$-rh $\mathrm{B}$ at ambient conditions, i.e. $\mathrm{V}, \mathrm{Cr}, \mathrm{Fe}$ and $\mathrm{Ni}$ [13]. The TEP temperature dependence of $\mathrm{Zr}$ doped $\beta$-rh $\mathrm{B}$ is qualitatively similar to that in $\mathrm{B}: \mathrm{V}$ and $\mathrm{B}: \mathrm{Fe}$. Considering the literature data on $\mathrm{Zr}$-poor $\beta$-rh $\mathrm{B}$ (about $600 \mu \mathrm{VK}^{-1}$ for $\mathrm{Zr}_{0.94} \mathrm{~B}_{99.06}$ at $300 \mathrm{~K}$ [18]), a certain reduction of thermopower values takes place at lower $\mathrm{Zr}$ contents $(<1.88$ at.\% $\mathrm{Zr})$, but Seebeck coefficients remains positive, moderately decreasing up to $\sim 2.4$ at.\% $\mathrm{Zr}$ where a steep change to negative values occurs. The jump is considerably larger than that in B:Fe, while the amounts of doped metal at the crossover from positive to negative TEP values are comparable in both $\mathrm{Zr}$ and Fe solid solutions. The data for $n$-type Fe-doped $\beta$-rh $\mathrm{B}$ as well as for $n$-type $\mathrm{Zr}$-doped $\beta$-rh $\mathrm{B}$ indicate a sign reversal to positive values at high temperatures. According to structural studies, the dopant atoms distributions in two structures are different. Fe atoms in the $\beta$-rh $\mathrm{B}$ structure are accommodated in the interstitial sites $A_{1}$ and $D$ only $[13,21,52,53]$. In both sites, the occupancy increases linearly with the Fe content and the variation of the lattice parameters does not show significant anomalies. From an electronical point of view, the $p-n$ transition is accompanied by a correlation among the diluted Fe atoms generating a specific system of electronic states in the band gap [13]. When a critical value of this correlation is crossed, the quality of electronic transport changes abruptly. In more recent work, the origin of the $p-n$ crossover was attributed to the certain changes in crystalline structure which might be restricted to the details of structural elements according to the analysis of the phonon spectra [21]. In contrast, the dopant atoms in $\mathrm{Zr}$-doped $\beta$-rh $\mathrm{B}$ are distributed within two major sites, $E$ and $D$. Our careful single crystal studies elucidated three more sites $\left(F, N\right.$, and $\left.A_{1}\right)$ available to accommodate minor quantities of $\mathrm{Zr}$. Both lattice parameters and major dopant atom sites occupancies evaluated by Rietveld refinement of XRD powder data exhibited perceptible deviation from linearity at the $p-n$ transition. The 
increasing of minor sites occupancies and defects on boron sites seems to be vital for the overall enlargement of $\mathrm{Zr}$ content in the $\beta$-rh $\mathrm{B}$ structure. The coincidence of jump position in Seebeck coefficient vs $\mathrm{Zr}$ content dependencies (Fig. 7) with anomalies in atom site occupancies and lattice parameters within 1.88 at.\% - 2.75 at.\% $\mathrm{Zr}$ doping range (Fig. 3 and Fig. 4) suggest a possible correlation between these parameters in good agreement with the studies on Fe-doped $\beta$-rh B [21]. Current work leaves a room for further experiments (Raman- and IR-active phonons spectra measurements) to illuminate the changes in structural discontinuities. The electronic properties studies via electron structure calculations are in progress in order to understand the effects of metal concentrations on the control of $p-n$ characteristics. From a practical point of view, the huge variation in the Seebeck coefficient values from positive to negative we find in $\mathrm{Zr}$-doped $\beta$-rh $\mathrm{B}$ is quite striking. With the rare $n$ type behavior reaching values of $-600 \mu \mathrm{VK}^{-1}$, it is significantly larger than the $-200 \mu \mathrm{VK}^{-1}$ observed in $\mathrm{YAlB}_{14}$ with varying $\mathrm{Al}$ occupancy which has recently gained sizable attention [54-57].

\section{Acknowledgements}

The work of O.S. and L.S. was partly supported by Austrian FWF project V279-N19. Collaboration with XRC TU Wien (Dr. Klaudia Hradil) is highly appreciated. T.M. acknowledges support from CREST, JST. 


\section{References}

1. C. Wood, High-temperature thermoelectric energy conversion - II. Materials survey, Energ. Convers. Manag. 24 (1984) 331-343.

2. T. Mori, Higher borides, in: K.A. Gschneidner, Jr., J.-C. Bunzli, V.K. Pecharsky (Eds.) Handbook on the Physics and Chemistry of Rare Earths, Elsevier B.V., 38 (2008) 105-173.

3. G.A. Slack, K.E. Morgan, Some crystallography, chemistry, physics, and thermodynamics of $\mathrm{B}_{12} \mathrm{O}_{2}, \mathrm{~B}_{12} \mathrm{P}_{2}, \mathrm{~B}_{12} \mathrm{As}_{2}$, and related alpha-boron type crystals, J. Phys. Chem. Solids 75 (2014) 1054-1074.

4. A. Sussardi, T. Tanaka, A. U. Khan, L. Schlapbach, T. Mori, Enhanced thermoelectric properties of samarium boride, J. Materiom. 1 (2015) 196-204.

5. T. Mori, T. Nishimura, Thermoelectric properties of homologous p- and n-type boron-rich borides, J. Solid State Chem. 179 (2006) 2908-2915.

6. O. Sologub, Y. Matsushita, T. Mori, An $\alpha$-rhombohedral boron-related compound with sulfur: synthesis, structure and thermoelectric properties, Scr. Mater. 68 (2013) 289-292.

7. G.A. Slack, C.I. Hejna, M.F. Garbauskas, J.S. Kasper, The crystal structure and density of $\beta$-rhombohedral boron, J. Solid State Chem. 76 (1988) 52-63.

8. T. Ogitsu, E. Schwegler, G. Galli, $\beta$-Rhombohedral boron: at the crossroads of the chemistry of boron and the physics of frustration, Chem. Rev. 113 (2013) 3425-3449.

9. T. Ogitsu, F. Gygi, J. Reed, Y. Motome, E. Schwegler, G. Galli, Imperfect crystal and unusual semiconductor: boron, a frustrated element, J. Am. Chem. Soc. 131 (2009) 19031909.

10. S. Hoffmann, H. Werheit, Phase transition in $\beta$-rhombohedral boron near $550 \mathrm{~K}$, Solid State Sciences 14 (2012) 1572-1577.

11. E.D. Jemmis, D.L.V.K. Prasad, Icosahedral $\mathrm{B}_{12}$, macropolyhedral boranes, $\beta$ rhombohedral boron and boron-rich solids, J. Solid State Chem. 179 (9) (2006) 2768-2774. 
12. G.A. Slack, C.I. Hejna, M.F. Garbauskas, J.S. Kasper, X-Ray study of transition-metal dopants in $\beta$-boron, J. Solid State Chem. 76 (1988) 64-86.

13. H. Werheit, On the exceptional negative Seebeck effect in $3 d$-doped $\beta$-rhombohedral boron, Solid State Sciences 13 (2011) 1786-1796, and references therein.

14. B. Albert, H. Hillebrecht, Boron: elementary challenge for experimenters and theoreticians, Angew. Chem. Int. Ed. 48 (2009) 8640-8668.

15. H. Kim, K. Kimura, Vanadium concentration dependence of thermoelectric properties of $\beta$-rhombohedral boron prepared by spark plasma sintering, Mat. Trans. 52 (2011) 41-48.

16. H. Matsuda, T. Nakayama, K. Kimura, Y. Murakami, H. Suematsu, M. Kobayashi, I. Higashi, Structural and electronic properties of $\mathrm{Li}$ - and $\mathrm{Cu}$-doped $\beta$-rhombohedral boron constructed from icosahedral and truncated icosahedral clusters, Phys. Rev. B 52 (1995) 6102.

17. H. Matsuda, N. Tanaka, T. Nakayama, K. Kimura, Y. Murakami, H. Suematsu, M. Kobayashi, I. Higashi, Structural- and electronic-property investigations on metal-doped $\beta$ rhombohedral boron, J. Phys. Chem. Solids 57 (1996 ) 1167-1174.

18. T. Nakayama, J. Shimizu, K. Kimura, Thermoelectric properties of metal-doped $\beta$ rhombohedral boron, J. Solid State Chem. 154 (2000) 13-19.

19. K. Soga, A. Oguri, S. Araake, M. Terauchi, A. Fujiwara, K. Kimura, Li- and Mg-doping into icosahedral boron crystals, $\alpha$ - and $\beta$-rhombohedral boron, targeting high-temperature superconductivity: structure and electronic states, Solid State Chem. 177 (2004) 498-506.

20. H. Hyodo, S. Araake, S. Hosoi, K. Soga, Y. Sato, M. Tarauchi, K. Kimura, Structure and electronic properties of Mg-doped $\beta$-rhombohedral boron constructed from icosahedral clusters, Phys. Rev. B 77 (2008) 024515.

21. H. Werheit, V. Filipov, U. Kuhlmann, T. Dose, T. Lundström, Fe-doped $\beta$-Rhombohedral boron: Structural changes at the p-type/n-type transition, Solid State Sciences 47 (2015) 7-12. 
22. K. Kimura, M. Takeda, M. Fujimori, R. Tamura, H. Matsuda, R. Schmechel, H. Werheit, A unified picture for icosahedral cluster solids in boron-based and aluminum-based compounds, J. Solid State Chem. 133 (1997) 302-309.

23. H. Werheit, R. Schmechel, V. Kueffel, T. Lundström On the electronic properties of $\beta$ rhombohedral boron interstitially doped with $3 \mathrm{~d}$ transition metal atoms, J. Alloys Comp. 262263 (1997) 372-380.

24. B. Callmer, L.-E. Tergenius, J.O. Thomas, X-ray powder profile refinement of zirconium in $\beta$-rhombohedral boron, Solid State Chem. 26 (1978) 275-279.

25. T. Nakayama, K. Tanaka, J. Shimizu, K. Kimura, Thermoelectric properties of metaldoped $\beta$-rhombohedral boron, Proc. $17^{\text {th }}$ Intern. Conf. Thermoelectrics, IEE, 1998, 570-573.

26. H.K. Kim, T. Nakayama1, J. Shimizu, K. Kimura, Effects of metal doping on thermoelectric properties of arc-melted and hot-pressed $\beta$-rhombohedral boron, Mat. Trans. 49(3) (2008) 593-599.

27. Bruker Advanced X-ray solutions. APEX2 User Manual. Version 1.22, Bruker AXS Inc., 2004.

28. Bruker. APEXII, SAINT and SADABS., Bruker Analytical X-ray Instruments Inc.: Madison, Wisconsin, USA, 2008.

29. A.C.T. North, D.C. Phillips, F.S. Mathews, A semi-empirical method of absorption correction, Acta. Crystallogr. A, 24 (1968) 351-359.

30. P. McArdle, ABSEN- a PC computer program for listing systematic absences and spacegroup determination, J. Appl. Cryst. 29 (1996) 306.

31. L.J. Farrugia, WinGX suite for small-molecule single-crystal crystallography, J. Appl. Cryst. 32 (1999) 837-838.

32. G.M. Sheldrick, SHELXS-97, Program for the Solution of Crystal Structures, University of Göttingen, Germany, 1997. 
33. G.M. Sheldrick, G.M. SHELXL-97, Program for Crystal Structure Refinement, University of Göttingen, 1997.

34. E. Parthe, L.M. Gelato, The standardization of inorganic crystal-structure data, Acta Cryst. A40 (1984) 169- 183.

35. J. Rodriguez-Carvajal, Recent Developments of the Program FULLPROF, Commission on Powder Diffraction (IUCr). Newsletter 26 (2001) 12-19.

36. D. Berthebaud, A. Sato, Y. Michiue, T. Mori, A. Nomura, T. Shishido, K. Nakajima, Effect of transition element doping on crystal structure of rare earth borosilicides $\mathrm{REB}_{44} \mathrm{Si}_{2}, \mathrm{~J}$. Solid State Chem. 184 (2011) 1682-1687.

37. O. Sologub, L.P. Salamakha, B. Stöger, P.F. Rogl, H. Michor, E. Bauer Incorporation of platinum atoms in a silicon-free boride of the $\mathrm{YB}_{50}$-type structure J. Alloys Comp. 675 (2016) 104-115.

38. T. Lundström, L.E. Tergenius, I. Higashi, A single-crystal investigation of the solid solution $\mathrm{NiB}_{48.5}$ of $\beta$-rhombohedral boron type structure, Z. Kristallogr. 167 (1984) 235-246. 39. I. Higashi, T. Ishii, Two-dimensional icosahedral $B_{12}$ networks in boron-rich crystals, Forma 16 (2001) 187-207.

40. M. Tillard-Charbonnel, A. Manteghetti, C. Belin, Icosahedron oligomerization and condensation in intermetallic compounds. Bonding and electronic requirements, Inorg. Chem. 39 (2000) 1684-1696.

41. B.J. Callmer, A Single-Crystal Diffractometry Investigation of scandium in $\beta$ rhombohedral boron, J. Solid State Chem. 23 (1978) 391-398.

42. N. Vojteer, J. Stauffer, H. Hillebrecht, K. Hofmann, M. Panda, B. Albert Lithium intercalation into $\beta$-rhombohedral boron: $\mathrm{LiB}_{\sim 10}$ or $\mathrm{Li}_{30} \mathrm{~B}_{309}$, Z. Anorg. Allg. Chem. 635 (2009) 653-659. 
43. M. Kobayashi, I. Higashi, H. Matsuda, K. Kimura, Rietveld analysis of $\operatorname{LiB}_{13}$ with $\beta$ rhombohedral boron structure, J. Alloys Compd. 221 (1995) 120-124.

44. G. Giunchi, L. Malpezzi, N. Masciocchi, A new crystalline phase of the boron-rich metalboride family: the $\mathrm{Mg}_{2} \mathrm{~B}_{25}$ species, Solid State Sci. 8 (2006) 1202-1208

45. V. Adasch, K.-U. Hess, T. Ludwig, N. Vojteer, H. Hillebrecht, Synthesis, crystal growth and structure of $\mathrm{Mg}$ containing $\beta$-rhombohedral boron: $\mathrm{MgB}_{17.4}$, J. Solid State Chem. 179 (2006) 2900-2907.

46. S. Brutti, M. Colapietro, G. Balducci, L. Barba, P. Manfrinetti, A. Palenzona, Synchrotron powder diffraction Rietveld refinement of $\mathrm{MgB}_{20}$ crystal structure, Intermetallics 10 (2002) 811-817.

47. N.F. Mott, E.A. Davis, Electronic Processes in Non-Crystalline Materials, Clarendon Press, Oxford, 1971.

48. D. Emin, T. Holstein, Ann. Phys. 53 (1969) 439.

49. W. Brenig, G.H. Döhler, P. Wölfle, Thermally assisted hopping transport in disordered systems, Z. Phys. 258 (1973) 381-400.

50. I. P. Zvyagin, On the theory of hopping transport in disordered semiconductors, Phys. Status Solidi (b), 58 (1973) 443-449.

51. H. Overhof, Thermopower calculation for variable range hopping - application to $\alpha-\mathrm{Si}$, Phys. Status Solidi (b), 67 (1975) 709-714.

52. H. Werheit, K. de Groot, W. Malkemper, T. Lundström, On $n$-type $\beta$ rhombohedral boron, J. Less-Common Met. 82 (1982) 163-168.

53. U. Kuhlmann, H. Werheit, T. Dose, T. Lundström, Influence of interstitially soluted iron on structural, optical and electrical properties of $\beta$-rhombohedral boron, J. Alloys Comp. 186 (1992) 187-200. 
54. S. Maruyama, Y. Miyazaki, K. Hayashi, T. Kajitani, T. Mori, Excellent $p-n$ control in a high temperature thermoelectric boride, Appl. Phys. Lett. 101 (2012) 152101.

55. R. Sahara, T. Mori, S. Maruyama, Y. Miyazaki, K. Hayashi, T. Kajitani, Theoretical and experimental investigation of the excellent $p-n$ control in yttrium aluminoborides, Sci. Technol. Adv. Mater. 15 (2014) 035012.

56. S. Maruyama, A. Prytuliak, Y. Miyazaki, K. Hayashi, T. Kajitani, T. Mori, Al insertion and additive effects on the thermoelectric properties of yttrium boride, J. Appl. Phys. 115 (2014) 123702.

57. S. Maruyama, T. Nishimura, Y. Miyazaki, K. Hayashi, T. Kajitani, T. Mori, Microstructure and thermoelectric properties of $\mathrm{Y}_{\mathrm{x}} \mathrm{Al}_{\mathrm{y}} \mathrm{B}_{14}$ samples fabricated through the spark plasma sintering, Mater. Renew. Sustain. Energy 3 (2014) 1. 


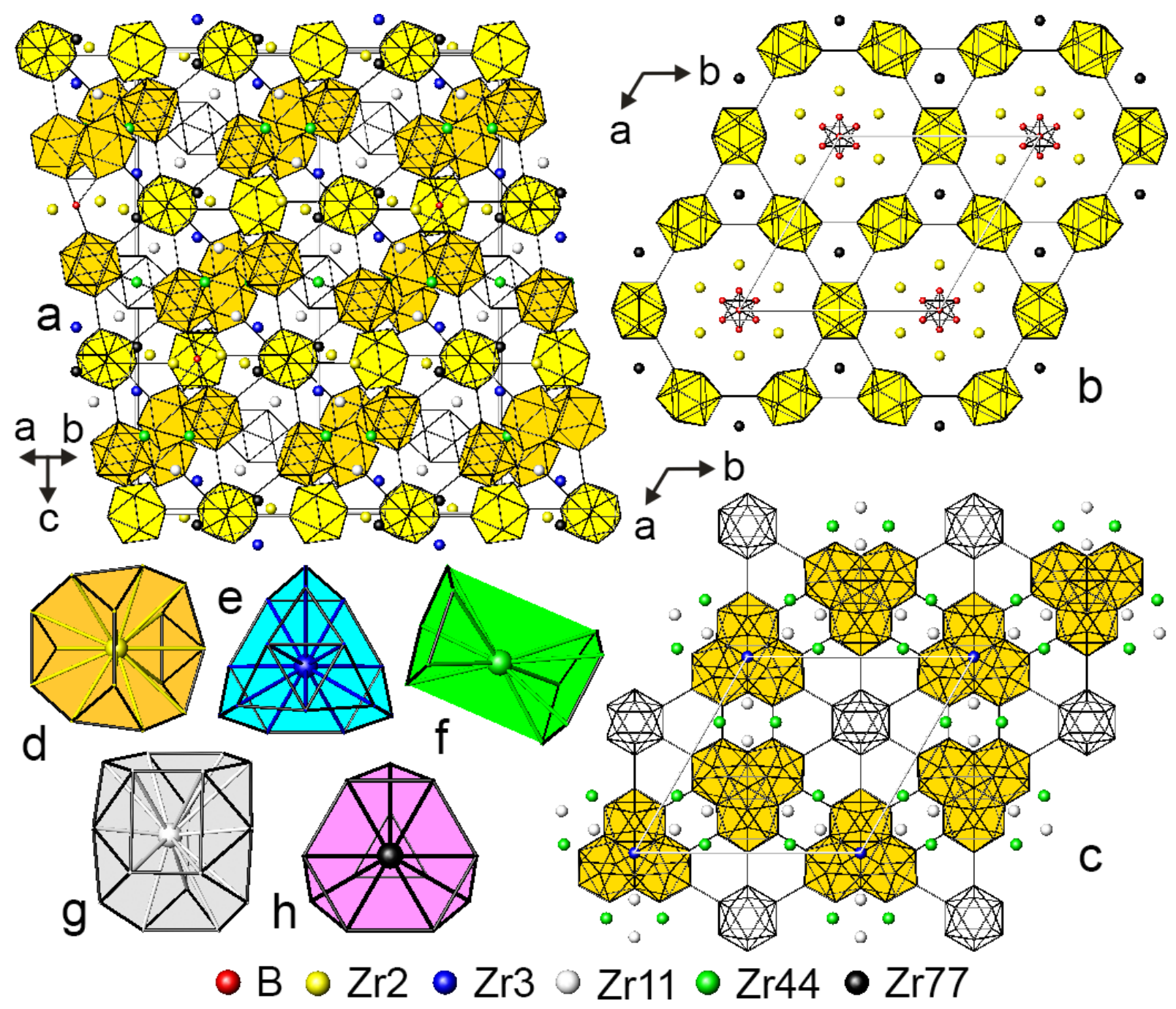

Fig. 1. (a) Polyhedral view of the $\beta$-rh $\mathrm{B}$ structure showing $\mathrm{B}_{28}$ (orange) and $\mathrm{B}_{12}$ (yellow and white for icosahedra of type II and type I respectively) clusters and location of partially occupied $\mathrm{Zr}$ atom sites ( $\mathrm{Zr}$ bonds are omitted). (b) Inter-linked $\mathrm{B}_{12}$ icosahedra (type II) along with $\mathrm{Zr2}$, Zr77, B13 and B15. (c) Triply-fused type III icosahedra ( $\mathrm{B}_{28}$ units) and $\mathrm{B}_{12}$ icosahedra (type I) along with Zr3, Zr11 and Zr44. (d) $D-$, (e) $E-$, (f) $F-$, (g) $N$ - and (h) $A_{l^{-}}$ voids filled with $\mathrm{Zr2}, \mathrm{Zr} 3, \mathrm{Zr} 44, \mathrm{Zr} 11$ and Zr77 respectively. In printed version, B - black balls, $\mathrm{Zr}$ - light-grey balls, $\mathrm{B}_{28}$ - dark grey units, isocahedra of type I and type II - white and light-grey units respectively. 

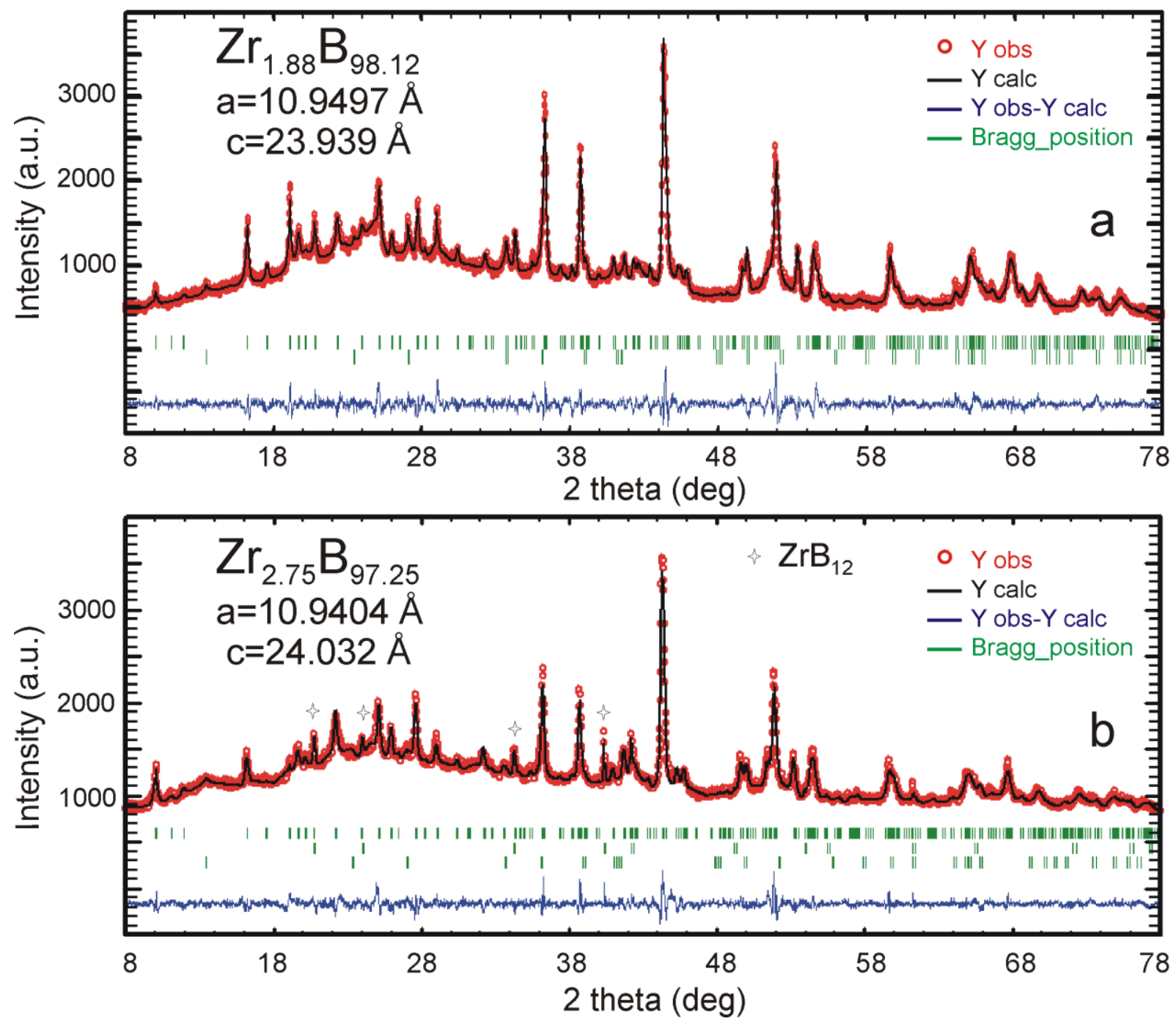

Fig. 2. Powder XRD patterns of metal-poor (a) and metal-rich (b) Zr-doped $\beta$-rh B. The solid line derives from Rietveld refinement. $Y_{\text {obs. }}-Y_{\text {calc. }}$ is the intensity difference between experimental data and Rietveld calculations. Lowest raw of Bragg positions corresponds to the $\beta-\mathrm{Si}_{3} \mathrm{~N}_{4}$ impurity originated from the mortar. 


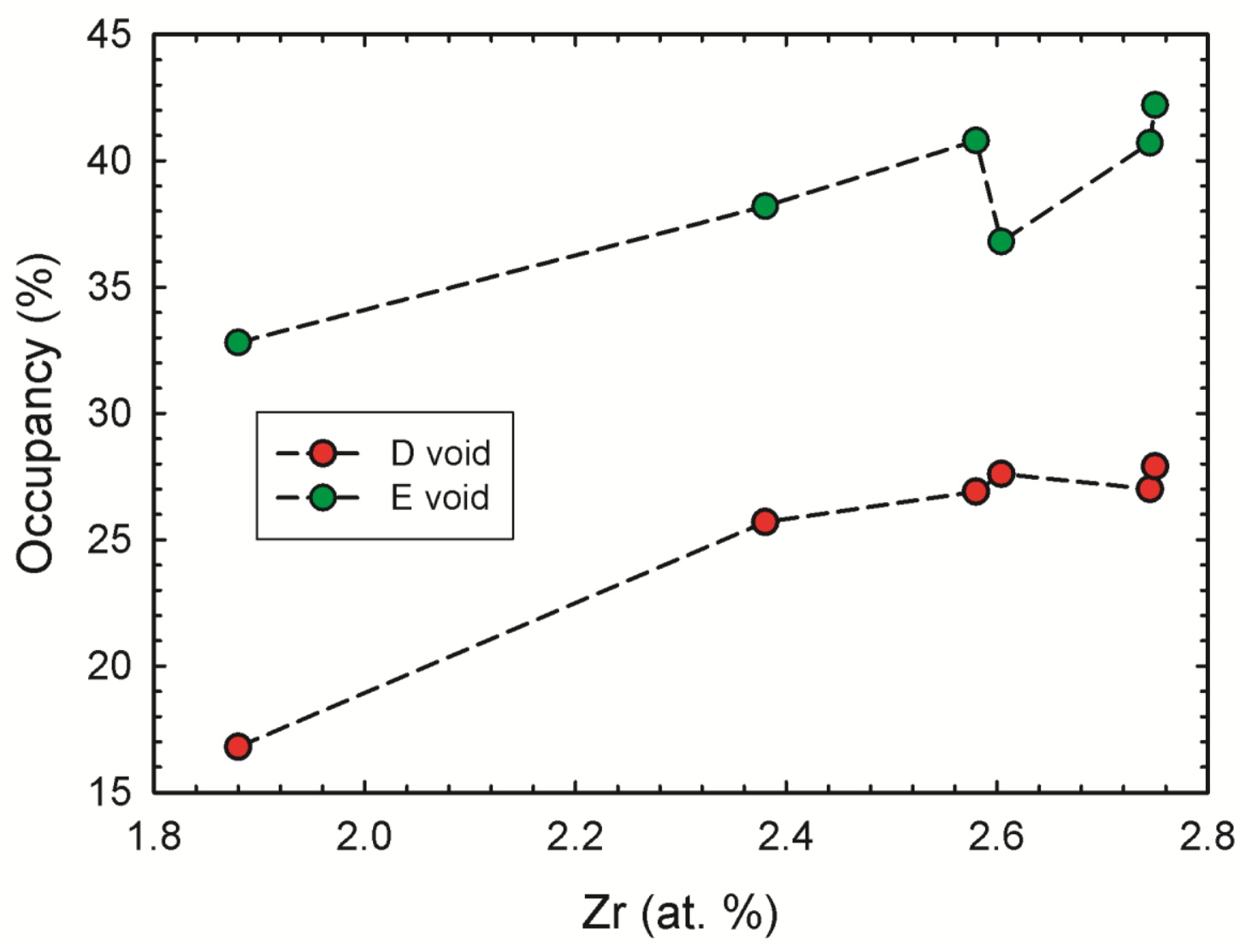

Fig. 3. Correlations between occupancies of $D$ - and $E$-sites and $\mathrm{Zr}$ content in $\mathrm{Zr}$-doped $\beta$-rh $\mathrm{B}$. 

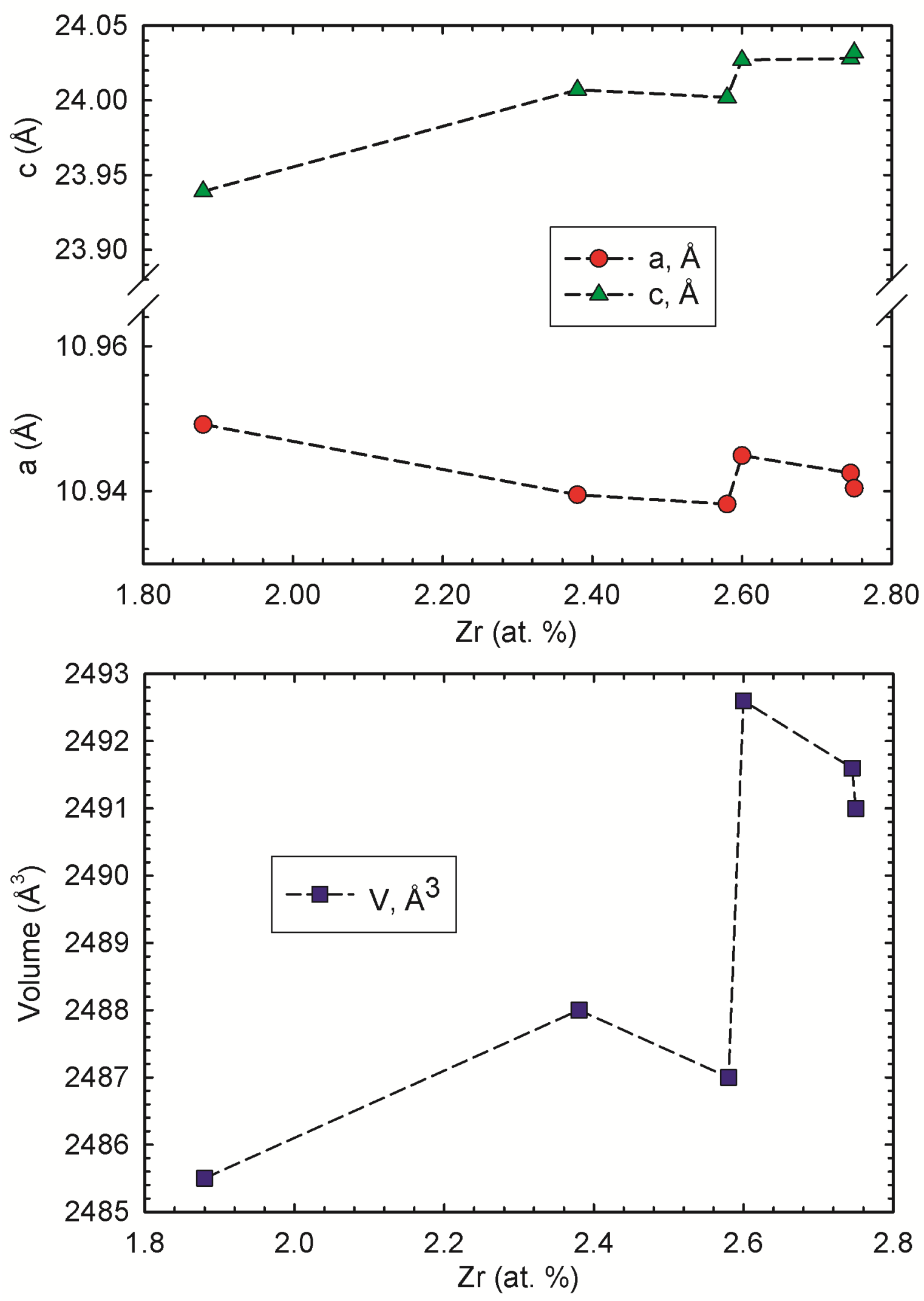

Fig. 4. Zr concentration dependence of lattice constants and volume in $\mathrm{Zr}$-doped $\beta$-rh $\mathrm{B}$. 


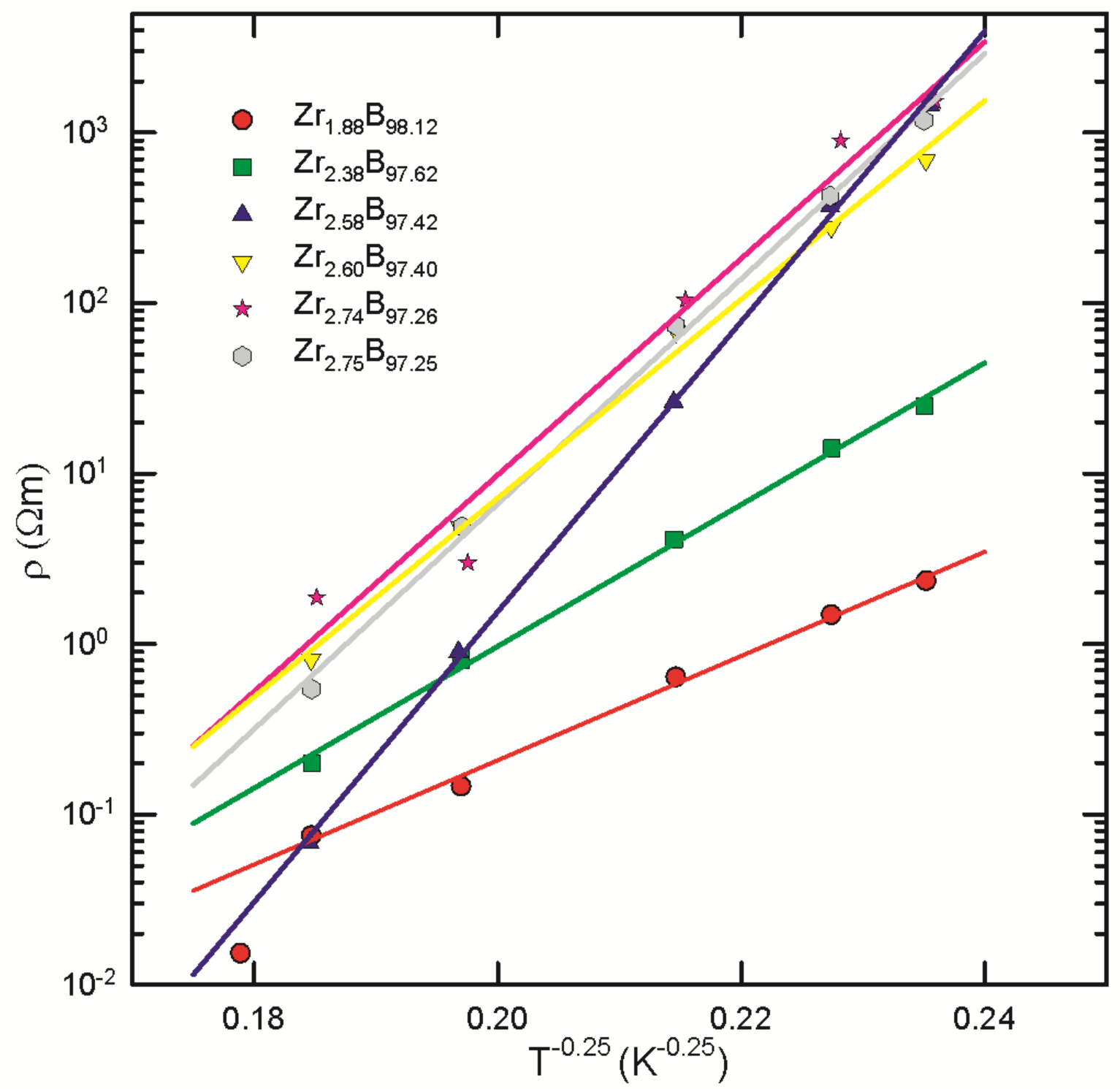

Fig. 5. Temperature dependence of resistivity of $\mathrm{Zr}$-doped $\beta$-rh B samples. The compositions are given as obtained from Rietveld refinement of powder XRD data. 


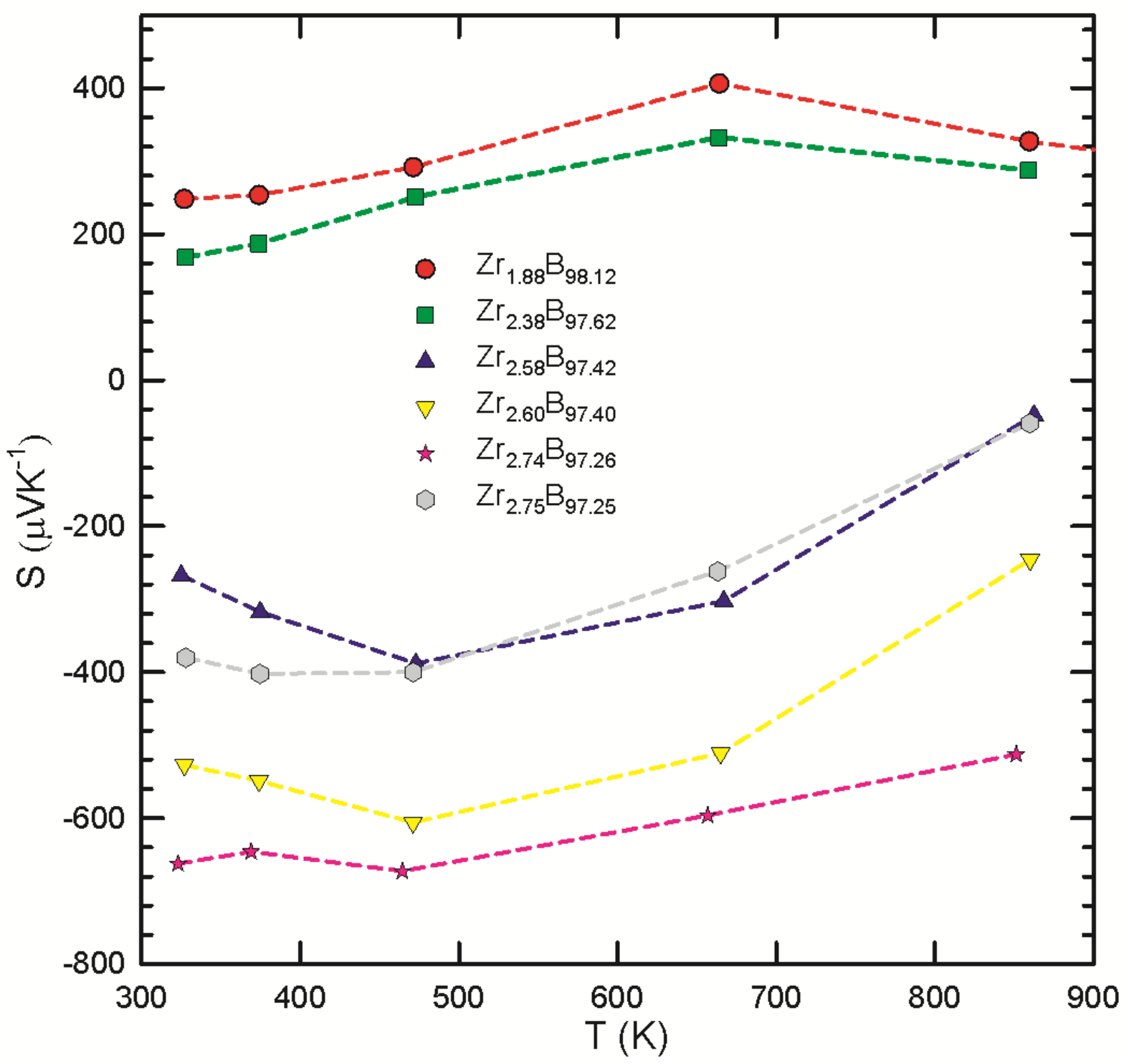

Fig. 6. Temperature dependence of thermopower of $\mathrm{Zr}$-doped $\beta$-rh $\mathrm{B}$ samples. The compositions are given as obtained from Rietveld refinement of XRD data. Dashed lines are guidance to eye. 


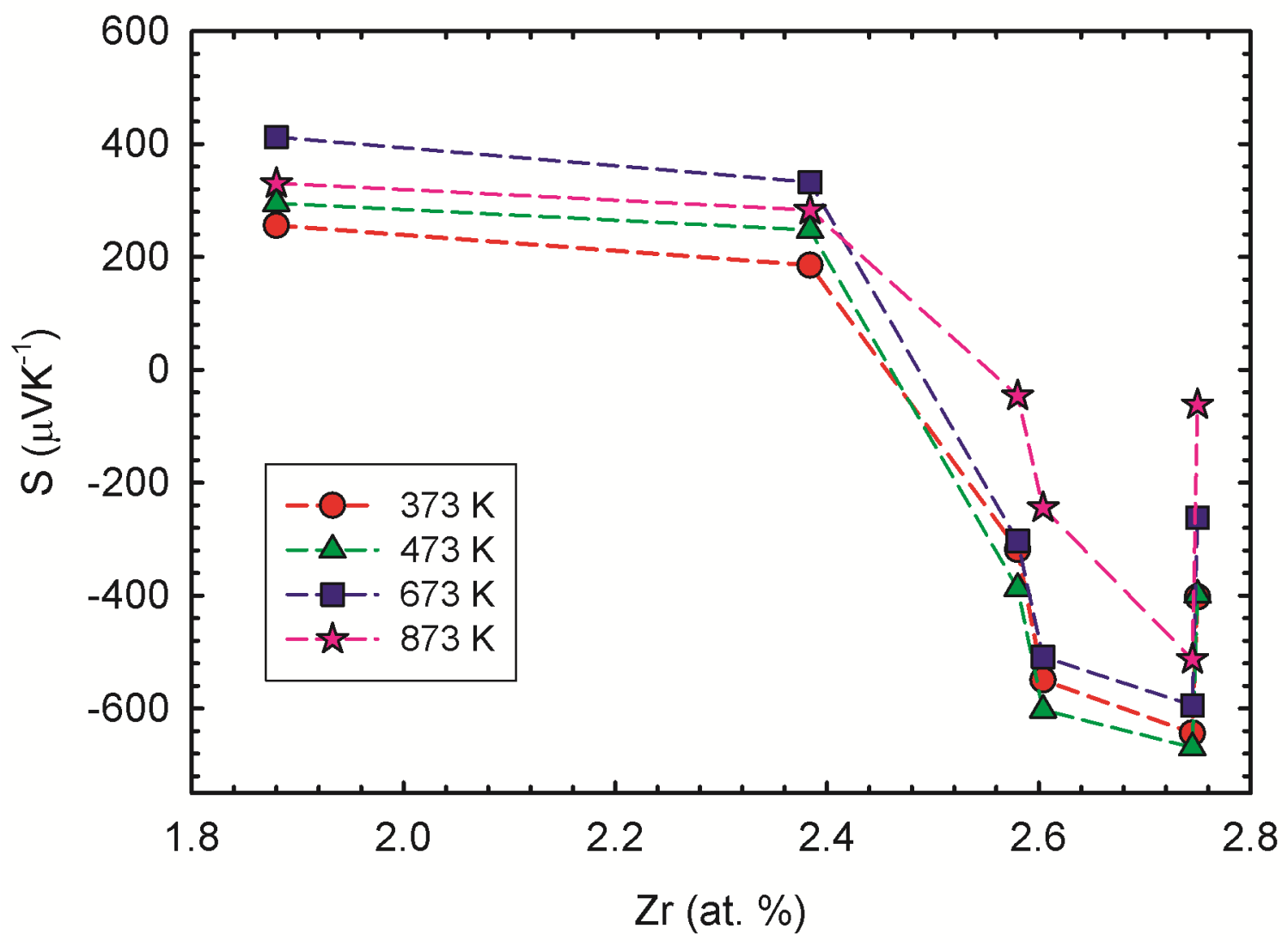

Fig. 7. Composition dependence of the Seebeck coefficient of $\mathrm{Zr}$-doped $\beta$-rh B. Dashed lines are guidance to eye. 
